\title{
Low-density lipoprotein cholesterol versus particle number in middle school children
}

\author{
Michele Mietus-Snyder, MD, \\ George Washington University School of Medicine \& Health Sciences, Children's National \\ Medical Center
}

Kimberly L. Drews, PhD, The George Washington University Biostatistics Center

James D. Otvos, PhD,

LipoScience, Inc.

Steven M. Willi, MD,

Children's Hospital of Philadelphia

Gary D. Foster, Ph.D., Center for Obesity Research and Education, Temple University

Russell Jago, PhD, and

Centre for Exercise, Nutrition \& Health Sciences, School for Policy Studies, University of Bristol

John B. Buse, MD PhD* on behalf of the HEALTHY Study Group

University of North Carolina School of Medicine

\section{Abstract}

Objectives-To characterize lipids and lipoproteins in a diverse school-based cohort and identify features associated with discordance between low-density lipoprotein cholesterol (LDLC) and LDL particle (LDL-P).

Study design-Sixth grade children enrolled in the HEALTHY trial $(n=2,384$; mean age $11.3 \pm$ $0.6 \mathrm{yr} ; 54.2 \%$ female) were evaluated for standard lipids, lipoprotein particles measured by nuclear magnetic resonance, and homeostatic model of insulin resistance (HOMA-IR). Characteristics of subgroups with values of LDL-C and LDL-P discordant by $>20$ percentile units, an amount reasoned to be clinically significant, were compared.

Results-Four hundred twenty-eight (18\%) of children were in the LDL-P < LDL-C subgroup and 375 (16\%) in the LDL-P > LDL-C subgroup. Those with LDL-P > LDL-C had significantly higher BMI, waist circumference, HOMA-IR, triglycerides, systolic and diastolic blood pressure, and reflected a greater Hispanic ethnic composition but fewer of black race than both the concordant (LDL-P $\cong$ LDL-C) and opposite discordant (LDL-P < LDL-C) subgroups.

(C) 2013 Mosby, Inc. All rights reserved.

Corresponding author: Kimberly L. Drews, PhD, The George Washington University Biostatistics Center, 6110 Executive Blvd, Suite 750, Rockville, MD 20882, Phone: 301-881-9260, Fax: 301-881-3767, kdrews@ @bs.gwu.edu.

*A list of members of the HEALTHY Study Group is available at www.jpeds.com (Appendix).

Publisher's Disclaimer: This is a PDF file of an unedited manuscript that has been accepted for publication. As a service to our customers we are providing this early version of the manuscript. The manuscript will undergo copyediting, typesetting, and review of the resulting proof before it is published in its final citable form. Please note that during the production process errors may be discovered which could affect the content, and all legal disclaimers that apply to the journal pertain.

The authors declare no conflicts of interest. 
Conclusions-There is as much lipoprotein cholesterol compositional heterogeneity in $6^{\text {th }}$ graders as has been described in adults and a discordant atherogenic phenotype of LDL-P > LDL$\mathrm{C}$, common in obesity, is often missed when only LDL-C is considered. Conversely, many children with moderate-risk cholesterol measures ( $75^{\text {th }}$ to $99^{\text {th }}$ percentile) have a lower LDL particle burden.

\section{Keywords}

Lipoproteins; Cardiovascular Risk; Obesity; Pediatrics; Primary Prevention

One of the modifiable risk factors for cardiovascular disease (CVD) is dyslipidemia, but the optimal biomarker(s) to capture this risk is debated. Decades of evidence support the role of cholesterol infiltration into the vascular wall in atherogenesis, with uptake of ectopic lipid leading to foam cell and fatty streak formation. Cholesterol enters the arterial wall in apolipoprotein $\mathrm{B}(\mathrm{apoB})$ containing lipoproteins, predominantly LDL, but the cholesterol content of LDL particles (LDL-P) varies widely such that LDL cholesterol (LDL-C) is not always an accurate estimate of LDL-P burden. Non-HDL-C (total cholesterol minus HDLC), captures the cholesterol content within all lipoprotein particles considered to be atherogenic, correlates more strongly with LDL-P than LDL-C, and is currently recommended as an alternate measure of atherosclerotic risk, especially in hypertriglyceridemic adults(1) and children.(2) LDL-lowering treatment in children is of proven benefit when LDL-C levels are extreme(3) but the continued substantial burden of CVD suggests that the full spectrum of lipoprotein-related risk for optimal primary prevention is neither adequately identified or managed.

There is incomplete prediction of risk by either LDL-C or non-HDL-C(4) and persistent cardiovascular risk in the face of aggressive cholesterol lowering therapies.(5) Both may be explained at least partially by disagreement between lipoprotein particle and cholesterol measures. LDL-P concentration can be modest in the face of elevated LDL-C (when LDL-P are particularly cholesterol-rich) and conversely can be substantial despite low LDL-C concentrations when LDL-P are cholesterol-depleted. In adult longitudinal studies, increased carotid intima media thickness and incident CVD events are more strongly predicted by baseline LDL-P assessed by apoB, nuclear magnetic resonance (NMR), or ion mobility, than by either LDL-C or non-HDL-C. $(6,7)$

Although levels and correlates of LDL-P have been recently described in small cohorts of children,(8) data from a population-based pediatric evaluation of sufficient size to permit assessment of discordance between cholesterol and lipoprotein particle measures have not been variable. This report evaluates the lipid and lipoprotein particle characteristics in a well-characterized, diverse, school-based cohort of $6^{\text {th }}$ graders,(9) and characterizes the clinical traits that are associated with the LDL-P burden.

\section{METHODS}

HEALTHY, a cluster randomized trial designed to investigate the effectiveness of an integrated lifestyle intervention in middle schools in the reduction of risk factors for type 2 diabetes (T2DM), has been described in full.(9) Schools were the unit of randomization, intervention, and analysis. Major inclusion criteria for schools were at least 50\% of children eligible for federally subsidized, free or reduced-priced meals and/or at least 50\% of its students whose race/ethnicity was black or Hispanic. The study was approved by the institutional review boards of all participating research institutions. All children for whom data were collected provided assent with parental consent. Baseline data on $6^{\text {th }}$ graders incorporated into these analyses include anthropometric measures, blood pressure, fasting 
insulin, glucose and lipid profiles. Fasting blood draws were ensured using a two step procedure: (1) the evening before data collection, the study staff called the students scheduled for the next day's blood draws to remind them not to eat any food or drink anything except water after midnight and not to eat breakfast and (2) at check-in, students were questioned about the last time they had anything to eat or drink and those who indicated they had not fasted were rescheduled but still received their incentive. To rule out any confounding of non-fasting sampling on glucose, insulin, or triglyceride values, a full sensitivity analysis was performed excluding any subjects with a baseline glucose over 99 $\mathrm{mg} / \mathrm{dl}$ and no study conclusions were altered. The principle outcome variable in this report, the LDL particle, is not affected by the fasting state. Pubertal status was individually selfreported in private using the validated Pubertal Development Scale(10) and converted to pubertal stage groups that are consistent with the five pubertal stages that have been outlined by Tanner. The homeostatic model of insulin resistance (HOMA-IR) was calculated to estimate insulin resistance using the formula: fasting glucose $[\mathrm{mmol} / \mathrm{L}] \times$ fasting insulin $[\mu \mathrm{U} / \mathrm{L}] \div 22.5$.

Plasma samples were collected in EDTA after a 12-14 hour fast and were separated on the morning of collection by centrifugation $\left(2500 \mathrm{rpm}, 4^{\circ} \mathrm{C}, 20 \mathrm{~min}\right)$. Lipid profiles including total cholesterol (TC), triglycerides (TG), and high density lipoprotein cholesterol (HDL-C) were measured by CDC-standardized direct assay. LDL-C was estimated using the Friedewald formula. Lipoprotein particle profiles were measured on archived frozen specimens by NMR spectroscopy using the LipoProfile-3 algorithm at LipoScience, Inc. (Raleigh, NC).(6) Very low density lipoprotein (VLDL), LDL, and HDL particle subclasses were quantified from the amplitudes of their spectroscopically-distinct lipid methyl group NMR signals. VLDL-P, LDL-P, and HDL-P are the totals of the particle number concentrations of their respective subclasses and their weighted-average particle sizes were calculated from the sum of the diameter of each subclass multiplied by its relative mass percentage estimated from the amplitude of its methyl NMR signal.(11) Results reported are from the $23846^{\text {th }}$ grade HEALTHY participants who provided informed consent for ancillary studies and for whom a frozen specimen was available for analysis.

\section{Statistical Analyses}

Means $( \pm \mathrm{SD})$, medians ( \pm quartile) or frequency distributions (for categorical variables) were used to summarize the characteristics for the complete sample. Percentile distributions of LDL-C and LDL-P were calculated and participants defined as having concordant or discordant levels if the difference between the two measures of LDL quantity were $\leq 20$ or $>20$ percentile units, respectively. Any definition of discordance is unavoidably subjective; we considered a difference of $>20$ percentile units to be reflective of a clinically meaningful difference in LDL burden. For example, an LDL-c at $75^{\text {th }}$ percentile, if associated with an LDL-P at $95^{\text {th }}$ percentile, might reflect the risk associated with the $95^{\text {th }}$ percentile of LDL-C, and visa versa. Regression models were fit for the association of concordance/discordance status with sex and race/ethnicity using the PROC GLIMMIX procedure and with anthropometric and lab values using the PROC MIXED procedure.(12) To adjust for the clustering of participants within schools, a random effect was included in the models. All models were adjusted for pubertal stage and sex was added as an additional covariate to all models except those assessing association between sex and discordance/concordance status. P-values along with adjusted means and $95 \%$ confidence intervals are reported. Whenever exploratory statistically significant group differences were found $(\mathrm{p}<.05)$, Bonferroni adjusted pair-wise comparisons were carried out to determine where the actual differences lie. Due to skewness, insulin, cholesterol molecules per LDL-P, HDL-P, TG and VLDL-P size were log transformed and LDL-P and VLDL-P were square root transformed to distribute data normally. The distributions for LDL-P size and HDL-P size were non- 
transformable and could not be subjected to the regression models although means and $95 \%$ confidence intervals are reported. When considered as a dichotomous variable above or below $75 \mathrm{nmol} / \mathrm{L}$ however, small LDL-P associated significantly with LDL-P $>75^{\text {th }}$ percentile, and with all variables associated with LDL-P (data not shown). Spearman rank correlations were estimated to assess the associations of LDL-C and LDL-P with clinical and laboratory characteristics, unadjusted for cluster of participants within schools. To illustrate how often discordant lipoprotein phenotypes might be missed by standard LDL or non-HDL cholesterol values, a cross tabulation of LDL-P in the $1^{\text {st }}$ quartile, $2^{\text {nd }}$ quartile, $3^{\text {rd }}$ quartile, between the $75^{\text {th }}$ and $95^{\text {th }}$ percentile and above the $95^{\text {th }}$ percentile for our sample with the equivalent breaks for LDL-C and non-HDL-C is presented with frequencies and percentage of participants in each category. As previously reported,(13) the power calculation for this study was based on detecting change in the prevalence of overweight and obesity. As such the p-values reported within this paper represent findings associated with secondary outcomes and are provided to help facilitate the interpretation of the data only with alpha set at 0.05 . All analyses were performed using SAS version 9.2 (SAS Institute, Cary, NC).

\section{RESULTS}

Baseline demographic, metabolic and lipoprotein characteristics from an ethnically diverse population of $23846^{\text {th }}$ grade children (mean age $11.3 \pm 0.57$ years) are presented in the first column of Table I. Data stratified by sex can be viewed in Table II (available at www.jpeds.com); the only clinically significant difference between males and females was Tanner stage. Puberty was more advanced in females, with $81.1 \%$ at or beyond Tanner 3 (vs. $43.9 \%$ in males). Over $30 \%$ of the cohort were obese (BMI $>95^{\text {th }}$ percentile) and $12.8 \%$ reported a positive first degree family history of diabetes. Numerous cardiometabolic risk factors showed a shift toward a higher risk profile, with a mean BMI percentile of $72.9 \pm$ $28.0 \%$, mean waist circumference (WC) above the $75^{\text {th }}$ percentile and mean systolic and diastolic blood pressures which approximated the $60^{\text {th }}$ percentile for 11 year olds, as defined by NHANES III.(14) Fasting glucose and insulin levels were elevated in this peripubertal population as compared with NHANES data, (15) consistent with the insulin resistance associated with the later stages of puberty.(16) Furthermore, there was evidence of progression towards pathologic insulin resistance for many children with $17.0 \%$ having impaired fasting glucose, $17.0 \%$ with fasting insulin levels $\geq 138.9 \mathrm{pmol} / \mathrm{L}$ ( $>20 \mu \mathrm{U} / \mathrm{ml}$ ) and $14.6 \%$ with HOMA-IR $\geq 5.0$.

Median and interquartile ranges for TC and HDL-C correspond very closely to those identified for American preadolescent children by the 1981 Lipid Research Clinic (LRC) Pediatric Prevalence Study (as reported for 10 to 14 year olds).(17) However, median and $75^{\text {th }}$ percentile values for LDL-C were 6 and $10 \%$ lower and fasting TG levels were 26 and $16 \%$ higher (for boys and girls respectively, data not shown) as compared with the LRC norms.

The median LDL-P concentration for the overall population (Table I) was $677 \mathrm{nmol} / \mathrm{L}$ (IQR $512-885)$, approximately half of the $50^{\text {th }}$ percentile value $(1300 \mathrm{nmol} / \mathrm{L})$ described in adults, 30 to $74 \mathrm{yr}$ of age.(6) When all of the interrelated elements of lipoprotein metabolism were included in a correlation matrix (Table III), the characteristics of children predisposed to higher LDL-P closely resemble what has been described in adults.(18) The strongest relationships $(|\mathrm{r}|>0.45$, all at $p<0.0001)$ were correlations between LDL-P and non-HDL$\mathrm{C}(\mathrm{r}=0.74)$, LDL-C $(\mathrm{r}=0.66)$, and the TG/HDL-C ratio $(\mathrm{r}=0.47)$ with inverse relationships evident between LDL-P and both LDL size $(r=-0.48)$ and HDL size $(r=$ -0.64 ). The well described relationship between HOMA-IR and BMI z-score (used in lieu of percentile to normalize the upper range of distribution) was also evident $(r=0.65)$, and both 
of these variables were more closely associated with LDL-P than either LDL-C or nonHDL-C.

The percentile difference between LDL-P and LDL-C was relatively normally distributed with discordance in some children exceeding \pm 50 percentile units (Figure). 1116 (46.8\%) children had LDL-P and LDL-C values within 12 percentile units, almost identical to the $50 \%$ reported for adults in a multi-ethnic population. ${ }^{9}$ LDL-C exceeded LDL-P by $>20$ percentile units in $428(18.0 \%)$ participants, identifying a group of children with relatively cholesterol-rich lipoprotein particles. LDL-P percentile exceeded LDL-C by the same margin in 375 children (15.7\%) who have LDL particles that are cholesterol-poor.

Table I shows that children in the subgroups defined by concordance or discordance between LDL-P and LDL-C differ significantly in the prevalence of other cardiovascular risk factors. The discordant subgroup with LDL-P > LDL-C had significantly higher BMI percentile, waist circumference, fasting insulin, HOMA-IR, and TG, but lower TC, LDL-C, and HDL-C than both other subgroups. The opposite characteristics, lower BMI percentile, waist circumference, fasting insulin and HOMA-IR and TG but higher HDL-C also distinguished the LDL-P < LDL-C subgroup from the concordant subgroup. Non-HDL-C in the LDL-P < LDL-C subgroup was significantly higher than in the concordant and LDL-P > LDL-C discordant subgroups, but did not distinguish the latter two groups from one another. Systolic and diastolic blood pressure were higher and Hispanic ethnicity more common, and black race was less common in the LDL-P > LDL-C discordant and concordant subgroups than in the LDL-P < LDL-C discordant subgroup, but did not distinguish the latter two groups.

In light of the strength such a robust data set offers for these comparative analyses, the few features in Table I that did not vary by concordant-discordant category are notable: sex (after adjustment for Tanner stage), white race, and fasting blood glucose were similar among all subgroups. The skewed distribution of LDL and HDL particle size did not permit statistical analysis by subgroup, but mean values rose across the LDL-P > LDL-C discordant to concordant to the LDL-P < LDL-C subgroups.

Cross tabulation of LDL-C and LDL-P variables (Table IV) illustrates that discordant lipoprotein phenotypes might be missed by a standard focus on either LDL or non-HDL cholesterol values, particularly when LDL-P exceeds LDL-C. In this cohort, $14 \%$ of the 1777 children with LDL-C $<102 \mathrm{mg} / \mathrm{dl}$ and $12 \%$ with non-HDL-C $<122 \mathrm{mg} / \mathrm{dl}$ (both $<75^{\text {th }}$ percentile) had LDL-P $>75^{\text {th }}$ percentile $(>886-2672 \mathrm{nmol} / \mathrm{L})$. Four percent of children with LDL-C $<86 \mathrm{mg} / \mathrm{dl}$ and $2 \%$ with non-HDL-C $<102 \mathrm{mg} / \mathrm{dl}$ (both $<50^{\text {th }}$ percentile) still had LDL-P above the $75^{\text {th }}$ percentile. Conversely, $22 \%$ of 120 children with LDL-C > $126 \mathrm{mg} / \mathrm{dl}$ and $11 \%$ with non-HDL-C $>150 \mathrm{mg} / \mathrm{dl}$ (both $>95^{\text {th }}$ percentile), but no children with LDL-C above the $99^{\text {th }}$ percentile $(160 \mathrm{mg} / \mathrm{dl})$, had LDL-P $<75^{\text {th }}$ percentile.

Clinical and metabolic variables together with elements of the lipid profile, other than LDL$\mathrm{C}$, can give considerable insight to the cardiovascular risk burden of LDL-P. In a multivariate model considering all correlates of LDL-P, $66.6 \%$ of the variation could be explained by the combination of waist circumference, TG/HDL-C, non-HDL-C and HOMAIR.

\section{DISCUSSION}

This study confirms the existence of wide variability in cholesterol content of low density lipoproteins in a large, diverse, school-based cohort, and suggests that the frequency with which measures of lipoprotein cholesterol content either under or overestimate lipoprotein particle concentration is very similar to what has been described in adults.(6) This does not 
refute decades of evidence supporting the absolute role of cholesterol in atherogenesis, but rather helps accentuate the importance of the apoB-tagged lipoprotein particle (apoB Lp) carriers of cholesterol for sterol infiltration within the vascular space.(19) Because all lipoproteins except for HDL-P contain apoB, the simple calculation of non-HDL-C is a surrogate measure for apoB that includes LDL-C and the more transient intermediate density lipoprotein cholesterol (reported in the LDL component of a lipid profile) and VLDL-C.(20) The hypertriglyceridemia of insulin resistance drives up large VLDL-C that are metabolized to small LDL, increasing LDL-P. Therefore, non-HDL-C correlates with LDL-P better than does LDL-C, but the correlation can still be moderately discordant in as many as $30 \%$ of adults(7) and in $12 \%$ of children in this cohort. Because the half life of LDL-P is considerably longer than for other apoB-containing lipoproteins,(21) LDL-P are closely approximated by apoB levels. ApoB levels were not measured in the HEALTHY cohort but very similar relationships would have been anticipated to what is described here for LDL-P. These findings may have relevance to the interpretation of pediatric lipid levels. Therapeutic interventions may be considered on the basis of elevated LDL-C or non-HDL-C levels (22) though CVD risk may be mitigated by a disproportionately smaller lipoprotein particle burden when LDL-P < LDL-C, with correspondingly fewer cardiometabolic risk factors. Conversely, when LDL-P > LDL-C, as recently discovered in the increasingly prevalent dyslipidemia of childhood obesity complicated by insulin resistance,(8) a significant burden of cardiometabolic risk may be underestimated based on normal or minimally elevated cholesterol levels.

Currently, adult risk score models aim to identify and treat persons at heightened CVD risk within ten years. Once adults enter a high risk pool, however, they have already had decades of accumulated subclinical disease, reducing the impact of most available interventions and at best only postponing a coronary event.(23) A more preemptive "causal exposure model" has been proposed to actively prevent subclinical progression of disease by treating known causes of CVD as soon as they are identified. $(23,24)$ Adolescents with combined dyslipidemia, defined as a TG/HDL-C ratio greater than only 2.5 , are more likely to express a proatherogenic lipid profile in early adulthood.(25) An unsettling plateau in the net rate of CVD deaths among young adults, ages $35-54 \mathrm{yr},(26)$ can be traced to the steady rise in childhood obesity and diabetes over the last 4 decades, reflected in the strong association between non-HDL-C and cardiometabolic risk.(27) LDL-P is a sensitive biomarker for the disordered lipoprotein cholesterol and triglyceride metabolism associated with central obesity and insulin resistance, and appears to be operative in this rising prevalence of CVD. $(7,28)$ Much of the variation in LDL-P levels in HEALTHY study children was associated with the same combination of cardiometabolic factors that place adults at high CVD risk, namely insulin resistance, visceral adiposity, hypertension, and combined dyslipidemia.

A lower absolute LDL-P burden in children has been previously described,(8) but most pediatric studies to date have focused not on LDL-P concentration but rather on its close correlate, the LDL particle size. LDL size heightens cardiovascular risk because small LDL are cleared from the circulation by LDL receptors with $1 / 2$ to $1 / 3$ the efficiency of larger LDL.(29) When insulin resistance impairs TG clearance and the liver generates larger and more TG-rich VLDL to compensate, particles themselves too large to enter the vascular wall, they are quickly metabolized to small LDL that linger longer in the vascular space with increased opportunity to foment atherogenesis. The larger mean LDL particle size and lower LDL-P concentration in youth as compared with adults may therefore contribute to the lag time between the onset of atherogenesis and the development of symptomatic CVD.

Reproducible and reliable early surrogates for cardiovascular disease will be necessary to delineate the dose-response for LDL-P associated CVD risk in youth, but current preventive pediatric cardiology guidelines for standard lipid profile screening and management $(2,30)$ 
provide insight into a disproportionate LDL-P burden however by highlighting moderate and high level "non-lipid" risk factors. In the HEALTHY cohort, the subgroup with LDL-P > LDL-C had significantly higher prevalence of features of the metabolic syndrome, including elevated TG, low HDL-C, systolic and diastolic hypertension and hyperinsulinism but not hyperglycemia. Insulin resistance drives the hyperinsulinism of youth that masks glucose elevation, but cannot attenuate full cardiometabolic sequelae. Additional non-lipid risk factors such as family history, obesity, and diabetes all heighten the hazard associated with either LDL-C or non-HDL-C elevation. These are not only children who fall in the moderate LDL-C risk zone between 110 and $130 \mathrm{mg} / \mathrm{dl}$, or comparable non-HDL-C risk zone between 125 and $145 \mathrm{mg} / \mathrm{dl}$. In this cohort, $14 \%$ of children with LDL-C $<102 \mathrm{mg} / \mathrm{dl}$ and $12 \%$ with non-HDL-C $<122 \mathrm{mg} / \mathrm{dl}$ (both $<75^{\text {th }}$ percentile) had LDL-P $>75^{\text {th }}$ percentile. The adjusted mean LDL-P concentration in this subgroup was 888 (95\% CI=853-923), 24\% higher than the mean for the $6^{\text {th }}$ grade population overall, and the 95 th percentile crossed the $1100 \mathrm{nmol} /$ L threshold set as a target for LDL-P reduction in high-risk adults.(7)

If there is good insulin sensitivity, a normal waist circumference, low non-HDL-C and TG/ HDL-C, a lower LDL-P burden can be predicted across a wide range of LDL-C levels. At LDL-C up to the $95^{\text {th }}$ percentile ( $126 \mathrm{mg} / \mathrm{dl}$ in this cohort), $50 \%$ of children still have LDL$\mathrm{P}$ below the $75^{\text {th }}$ percentile. Among the HEALTHY cohort, children with levels of LDL-C that exceed the current conservative pharmacologic treatment threshold of $160 \mathrm{mg} / \mathrm{dl}$ ( $99^{\text {th }}$ percentile) however, levels that might be associated with familial hypercholesterolemia, all fall into a significantly elevated $\left(>95^{\text {th }}\right.$ percentile) LDL-P category.

Although absolute LDL-P levels differ, the prevalence of discordance between LDL-C and LDL-P seen in children was comparable with what has been described in adults. These findings are not self-evident and suggest that a confluence of genetic and epigenetic factors may underlie this trait, just as genes involved in lipid metabolism contribute to absolute cholesterol and triglyceride levels. Forty-three genetic loci have been associated with plasma lipoprotein size, concentration and cholesterol content in a genome-wide analyses on 17,296 adults of European ancestry.(31) These hereditary factors can only explain a small fraction of lipid variability but may already be manifest in the lipid phenotype in youth and may be functional in the apparent differences in LDL phenotype previously described among children of different race and ethnicity. $(8,32)$ Our findings are consistent with a greater LDL-P burden in children of Hispanic ethnicity as compared with white or black race but the sample size was inadequate for definitive subgroup analyses.

As the HEALTHY study targeted minority middle school children at heightened risk for obesity, the findings herein are most relevant to comparable inner city youth who, for the complex reasons that underpin health disparity, remain at heightened risk for both obesity and its cardiometabolic complications.(33) Notwithstanding intertwined hereditary and socioeconomic determinants, the same anthropometric and metabolic factors known to influence the absolute levels of cholesterol, triglycerides and lipoprotein species across the lifespan, are predictive of the absolute LDL-P burden both in adults(18) and in this multiethnic cohort of school children. These risk factors are sensitive to lifestyle. Nutrition and exercise interventions that improve insulin sensitivity and weight distribution in adults also improve the lipid phenotype. $(34,35)$ The atherogenic combined dyslipidemia of childhood obesity, which elevates the TG/HDL-C ratio and non-HDL-C in the context of visceral obesity and insulin resistance, is associated with a discordant, high-risk LDL particle phenotype. This LDL-P > LDL-C pattern, with putative atherogenic consequences, is often missed if only LDL-C is considered. Conversely, many children with moderate risk cholesterol profiles (in the 75th to 99th percentile) but optimal weight and insulin sensitivity may have a lower than apparent LDL-P burden. Children who meet current pediatric criteria for pharmacologic lipid management will most likely have very elevated LDL-P levels. 


\section{Acknowledgments}

We wish to thank the administration, faculty, staff, students, and their families at the middle schools and school districts that participated in the HEALTHY study. HEALTHY intervention materials are available for download at http://www.healthystudy.org/.

Funded by the National Institute of Diabetes and Digestive and Kidney Diseases/National Institutes of Health (U01DK61230, U01-DK61249, U01-DK61231, and U01-DK61223) and the American Diabetes Association.

\section{REFERENCES}

1. Brunzell JD, Davidson M, Furberg CD, Goldberg RB, Howard BV, Stein JH, et al. Lipoprotein management in patients with cardiometabolic risk: consensus conference report from the American Diabetes Association and the American College of Cardiology Foundation. J Am Coll Cardiol. 2008 Apr 15.51:1512-1524. [PubMed: 18402913]

2. Kavey R-E, Simons-Morton DG, DeJesus JM. Expert Panel on Integrated Guidelines for Cardiovascular Health and Risk Reduction in Children and Adolescents, National Heart, Lung, and Blood Institute. Expert Panel on Integrated Guidelines for Cardiovascular Healthy and Risk Reduction in Children and Adolescents: summary report. Pediatrics. 2011; 128(Suppl 5):S213S256. [PubMed: 22084329]

3. Rodenburg J, Vissers MN, Wiegman A, van Trotsenburg AS, van der Graaf A, de Groot E, et al. Statin treatment in children with familial hypercholesterolemia: the younger, the better. Circulation. 2007 Aug 7.116:664-668. [PubMed: 17664376]

4. Sniderman AD, St-Pierre AC, Cantin B, Dagenais GR, Despres JP, Lamarche B. Concordance/ discordance between plasma apolipoprotein B levels and the cholesterol indexes of atherosclerotic risk. Am J Cardiol. 2003 May 15.91:1173-1177. [PubMed: 12745098]

5. Libby P. The forgotten majority: unfinished business in cardiovascular risk reduction. J Am Coll Cardiol. 2005 Oct 4.46:1225-1228. [PubMed: 16198835]

6. Otvos JD, Mora S, Shalaurova I, Greenland P, Mackey RH, Goff DC Jr. Clinical implications of discordance between low-density lipoprotein cholesterol and particle number. J Clin Lipidol. 2011; 5:105-113. [PubMed: 21392724]

7. Cromwell WC, Otvos JD, Keyes MJ, Pencina MJ, Sullivan L, Vasan RS, et al. LDL Particle Number and Risk of Future Cardiovascular Disease in the Framingham Offspring Study Implications for LDL Management. J Clin Lipidol. 2007 Dec.1:583-592. [PubMed: 19657464]

8. Burns SF, Lee S, Arslanian SA. In vivo insulin sensitivity and lipoprotein particle size and concentration in black and white children. Diabetes Care. 2009 Nov.32:2087-2093. [PubMed: 19675203]

9. Group HS, Foster GD, Linder B, Baranowski T, Cooper DM, Goldberg L, et al. A school-based intervention for diabetes risk reduction. N Engl J Med. 2010 Jul 29.363:443-453. [PubMed: 20581420]

10. Petersen AC, Crockett L, Richards M, Boxer A. A self-report measure of pubertal status: Reliability, validity, and initial norms. Journal of Youth and Adolescence. 1988; 17:117-133.

11. Jeyarajah EJ, Cromwell WC, Otvos JD. Lipoprotein particle analysis by nuclear magnetic resonance spectroscopy. Clin Lab Med. 2006 Dec.26:847-870. [PubMed: 17110242]

12. Donner, A.; Klar, N. Design and Analysis of Cluster Randomized Trials in Health Research. London: Arnold Publishers; 2000.

13. Otvos JD, Jeyarajah EJ, Cromwell WC. Measurement issues related to lipoprotein heterogeneity. Am J Cardiol. 2002 Oct 17.90:22i-29i.

14. Fernandez JR, Redden DT, Pietrobelli A, Allison DB. Waist circumference percentiles in nationally representative samples of African-American, European-American, and MexicanAmerican children and adolescents. J Pediatr. 2004 Oct.145:439-444. [PubMed: 15480363]

15. Duncan GE. Prevalence of diabetes and impaired fasting glucose levels among US adolescents: National Health and Nutrition Examination Survey, 1999-2002. Arch Pediatr Adolesc Med. 2006 May.160:523-528. [PubMed: 16651496] 
16. Moran A, Jacobs DR Jr, Steinberger J, Hong CP, Prineas R, Luepker R, et al. Insulin resistance during puberty: results from clamp studies in 357 children. Diabetes. 1999 Oct.48:2039-2044. [PubMed: 10512371]

17. Tamir I, Heiss G, Glueck CJ, Christensen B, Kwiterovich P, Rifkind BM. Lipid and lipoprotein distributions in white children ages 6-19 yr. The Lipid Research Clinics Program Prevalence Study. J Chronic Dis. 1981; 34:27-39. [PubMed: 7451637]

18. Kathiresan S, Otvos JD, Sullivan LM, Keyes MJ, Schaefer EJ, Wilson PW, et al. Increased small low-density lipoprotein particle number: a prominent feature of the metabolic syndrome in the Framingham Heart Study. Circulation. 2006 Jan 3.113:20-29. [PubMed: 16380547]

19. Tabas I, Williams KJ, Boren J. Subendothelial lipoprotein retention as the initiating process in atherosclerosis: update and therapeutic implications. Circulation. 2007 Oct 16.116:1832-1844. [PubMed: 17938300]

20. Ramjee V, Sperling LS, Jacobson TA. Non-high-density lipoprotein cholesterol versus apolipoprotein B in cardiovascular risk stratification: do the math. J Am Coll Cardiol. $2011 \mathrm{Jul}$ 26.58:457-463. [PubMed: 21777740]

21. Sniderman A, Vu H, Cianflone K. Effect of moderate hypertriglyceridemia on the relation of plasma total and LDL apo B levels. Atherosclerosis. 1991 Aug.89:109-116. [PubMed: 1793438]

22. Daniels SR. Screening and Treatment of Dyslipidemias in Children and Adolescents. Horm Res Paediatr. 2001; 76(suppl 1):47-51. [PubMed: 21778749]

23. Berry JD, Dyer A, Cai X, Garside DB, Ning H, Thomas A, et al. Lifetime risks of cardiovascular disease. N Engl J Med. 2012 Jan 26.366:321-329. [PubMed: 22276822]

24. Sniderman A, Lawler PR, Williams K, Thanassoulis G, De Graff J, Furberg CD. The causal exposure model of vascular disease. Clinical Science. 2012; 122:369-373. [PubMed: 22187965]

25. Weiss R, Otvos JD, Sinnreich R, Miserez AR, Kark JD. The triglyceride to high-density lipoprotein-cholesterol ratio in adolescence and subsequent weight gain predict nuclear magnetic resonance-measured lipoprotein subclasses in adulthood. J Pediatr. 2010 Jan.158:44-50. [PubMed: 20801459]

26. Ford ES, Capewell S. Coronary heart disease mortality among young adults in the U.S. from 1980 through 2002: concealed leveling of mortality rates. J Am Coll Cardiol. 2007 Nov 27.50:21282132. [PubMed: 18036449]

27. Li C, Ford ES, McBride PE, Kwiterovich PO, McCrindle BW, Gidding SS. Non-high-density lipoprotein cholesterol concentration is associated with the metabolic syndrome among US youth aged 12-19 years. J Pediatr. 2011 Feb.158:201-207. [PubMed: 20828715]

28. Mora S, Szklo M, Otvos JD, Greenland P, Psaty BM, Goff DC Jr, et al. LDL particle subclasses, LDL particle size, and carotid atherosclerosis in the Multi-Ethnic Study of Atherosclerosis (MESA). Atherosclerosis. 2007 May.192:211-217. [PubMed: 16765964]

29. Packard CJ, Demant T, Stewart JP, Bedford D, Caslake MJ, Schwertfeger G, et al. Apolipoprotein B metabolism and the distribution of VLDL and LDL subfractions. J Lipid Res. 2000 Feb.41:305318. [PubMed: 10681415]

30. Daniels SR, Greer FR. Committee on N. Lipid screening and cardiovascular health in childhood. Pediatrics. 2008 Jul.122:198-208. [PubMed: 18596007]

31. Chasman DI, Pare G, Mora S, Hopewell JC, Peloso G, Clarke R, et al. Forty-three loci associated with plasma lipoprotein size, concentration, and cholesterol content in genome-wide analysis. PLoS Genet. 2009 Nov.5:e1000730. [PubMed: 19936222]

32. Burns SF, Lee SJ, Arslanian SA. Surrogate Lipid Markers for Small Dense Low-Density Lipoprotein Particles in Overweight Youth. J Pediatr. Jul 17. [Epub ahead of print].

33. Beydoun MA, Wang Y. Socio-demographic disparities in distribution shifts over time in various adiposity measures among American children and adolescents: What changes in prevalence rates could not reveal. Int J Pediatr Obes. 2010 Aug 19.

34. Siri-Tarino PW, Williams PT, Fernstrom HS, Rawlings RS, Krauss RM. Reversal of small, dense LDL subclass phenotype by normalization of adiposity. Obesity (Silver Spring). 2009 Sep. 17:1768-1775. [PubMed: 19498345] 
35. Chainani-Wu N, Weidner G, Purnell DM, Frenda S, Merritt-Worden T, Pischke C, et al. Changes in emerging cardiac biomarkers after an intensive lifestyle intervention. Am J Cardiol. 2011 Aug 15.108:498-507. [PubMed: 21624543]

\section{Appendix}

The following individuals and institutions constitute the HEALTHY Study Group (* indicates principal investigator or director):

\section{Study Chair}

Children's Hospital Los Angeles: F.R. Kaufman.

\section{Field Centers}

Baylor College of Medicine: T. Baranowski*, L. Adams, J. Baranowski, A. Canada, K.T. Carter, K.W. Cullen, M.H. Dobbins, R. Jago, A. Oceguera, A.X. Rodriguez, C. Speich, L.T. Tatum, D. Thompson, M.A. White, C.G. Williams; Oregon Health \& Science University: L. Goldberg*, D. Cusimano, L. DeBar, D. Elliot, H.M. Grund, S. McCormick, E. Moe, J.B. Roullet, D. Stadler; Temple University: G. Foster* (Steering Committee Chair), J. Brown, B. Creighton, M. Faith, E.G. Ford, H. Glick, S. Kumanyika, J. Nachmani, L. Rosen, S. Sherman, S. Solomon, A. Virus, S. Volpe, S. Willi; University of California at Irvine: D. Cooper*, S. Bassin, S. Bruecker, D. Ford, P. Galassetti, S. Greenfield, J. Hartstein, M. Krause, N. Opgrand, Y. Rodriguez, M. Schneider; University of North Carolina at Chapel Hill: J. Harrell*, A. Anderson, T. Blackshear, J. Buse, J. Caveness, A. Gerstel, C. Giles, W. Hall, A. Jessup, P. Kennel, R. McMurray, A-M. Siega-Riz, M. Smith, A. Steckler, A. Zeveloff; University of Pittsburgh: M.D. Marcus*, M. Carter, S. Clayton, B. Gillis, K. Hindes, J. Jakicic, R. Meehan, R. Noll, J. Vanucci, E. Venditti; and University of Texas Health Science Center at San Antonio: R. Treviño*, A. Garcia, D. Hale, A. Hernandez, I. Hernandez, C. Mobley, T. Murray, J. Stavinoha, K. Surapiboonchai, Z. Yin.

\section{Coordinating Center}

George Washington University: K. Hirst*, K. Drews, S. Edelstein, L. El ghormli, S. Firrell, M. Huang, P. Kolinjivadi, S. Mazzuto, T. Pham, A. Wheeler.

\section{Project Office}

National Institute of Diabetes and Digestive and Kidney Diseases: B. Linder*, C. Hunter, M. Staten.

\section{Central Biochemistry Laboratory}

University of Washington Northwest Lipid Metabolism and Diabetes Research Laboratories: S.M. Marcovina*. 


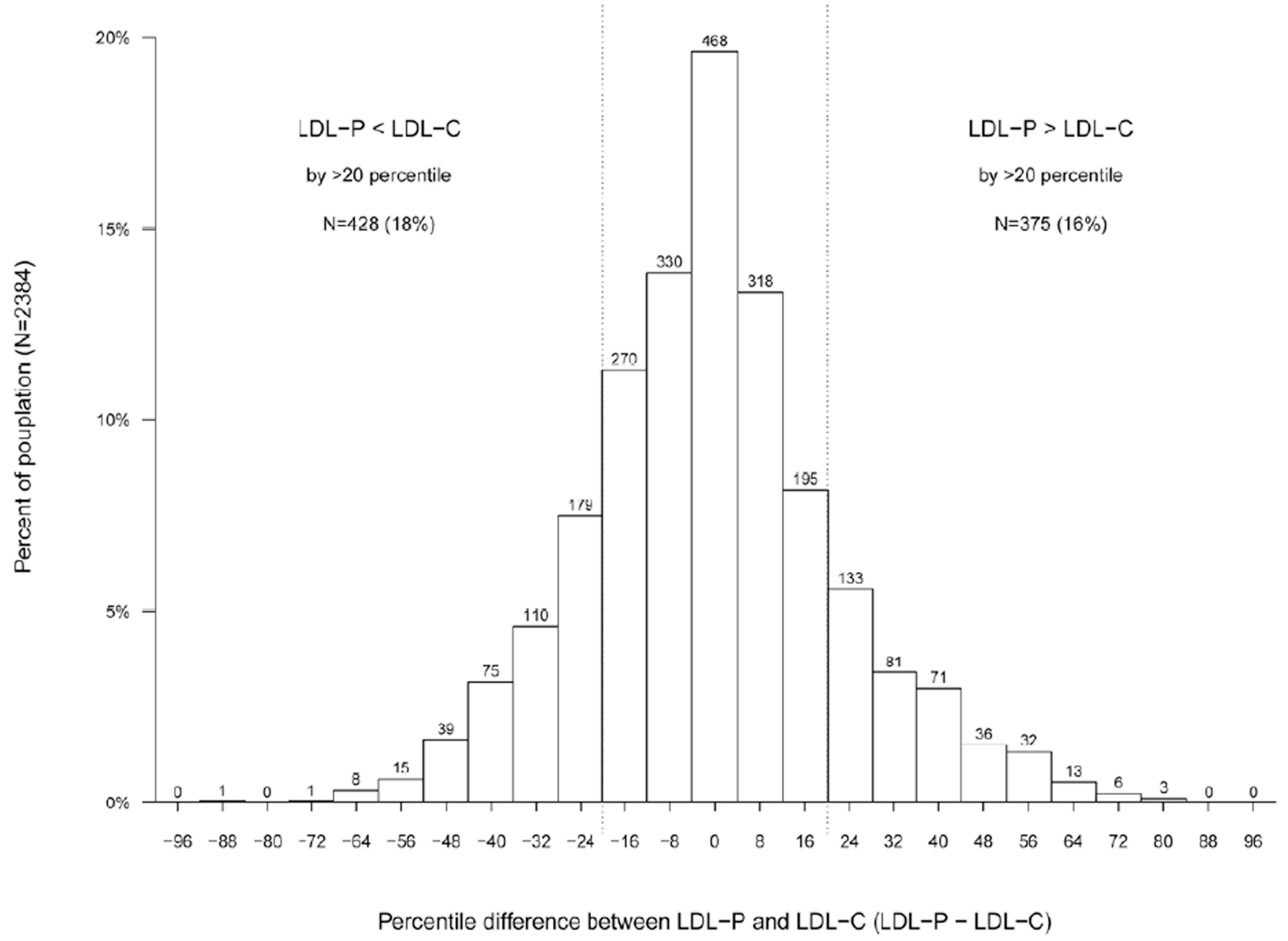

Figure 1.

Amount of agreement/disagreement between LDL-P and LDL-C as differences in the sample percentiles for each and the percent of the sample that falls into each range of differences. There is relative agreement or concordance for two-thirds of the study group in whom LDL-C and LDL-P percentiles fall within 20 percentile points. The two measures disagree or are discordant for the rest of the study group, varying from 20 to 80 percentile points. 


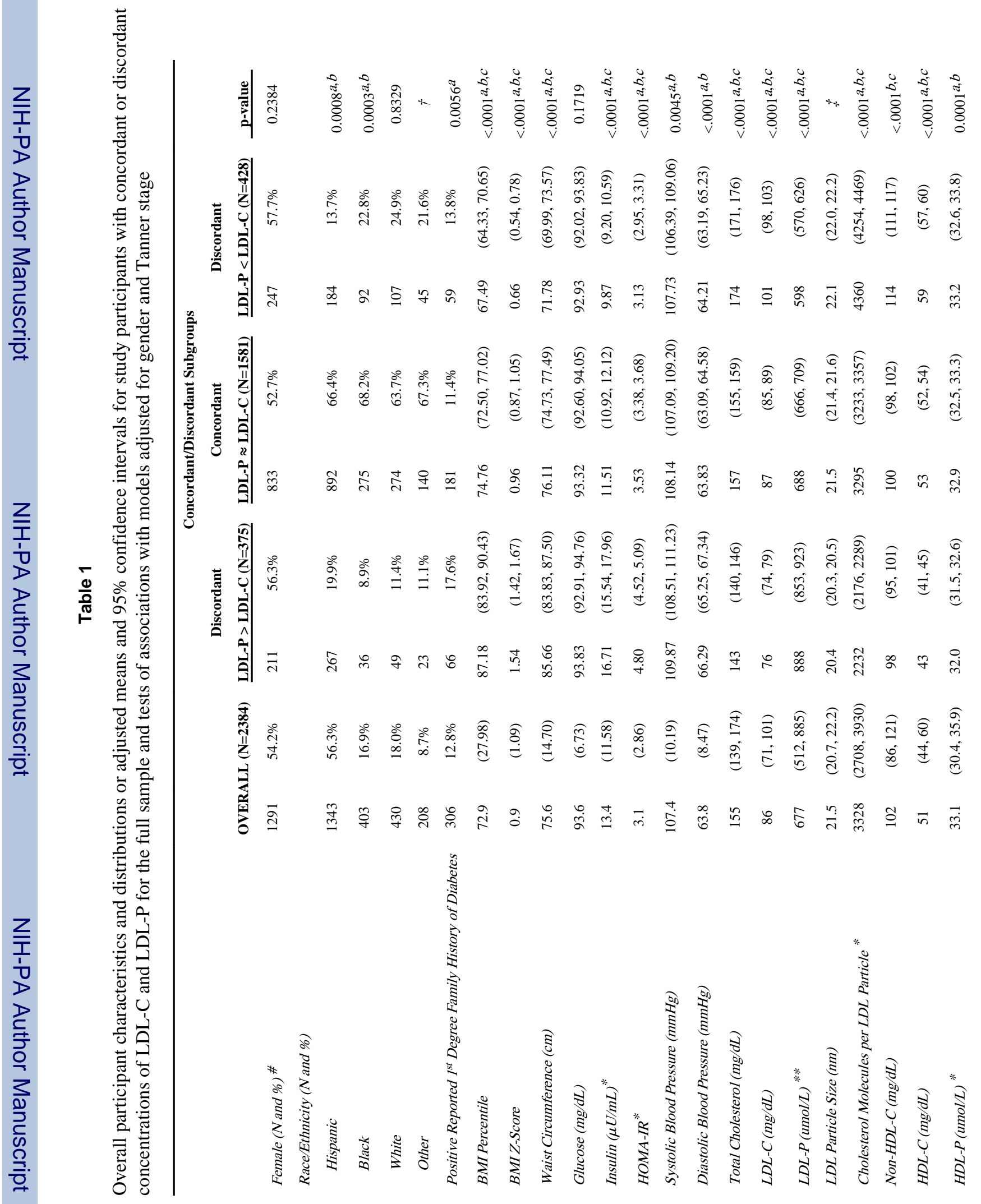




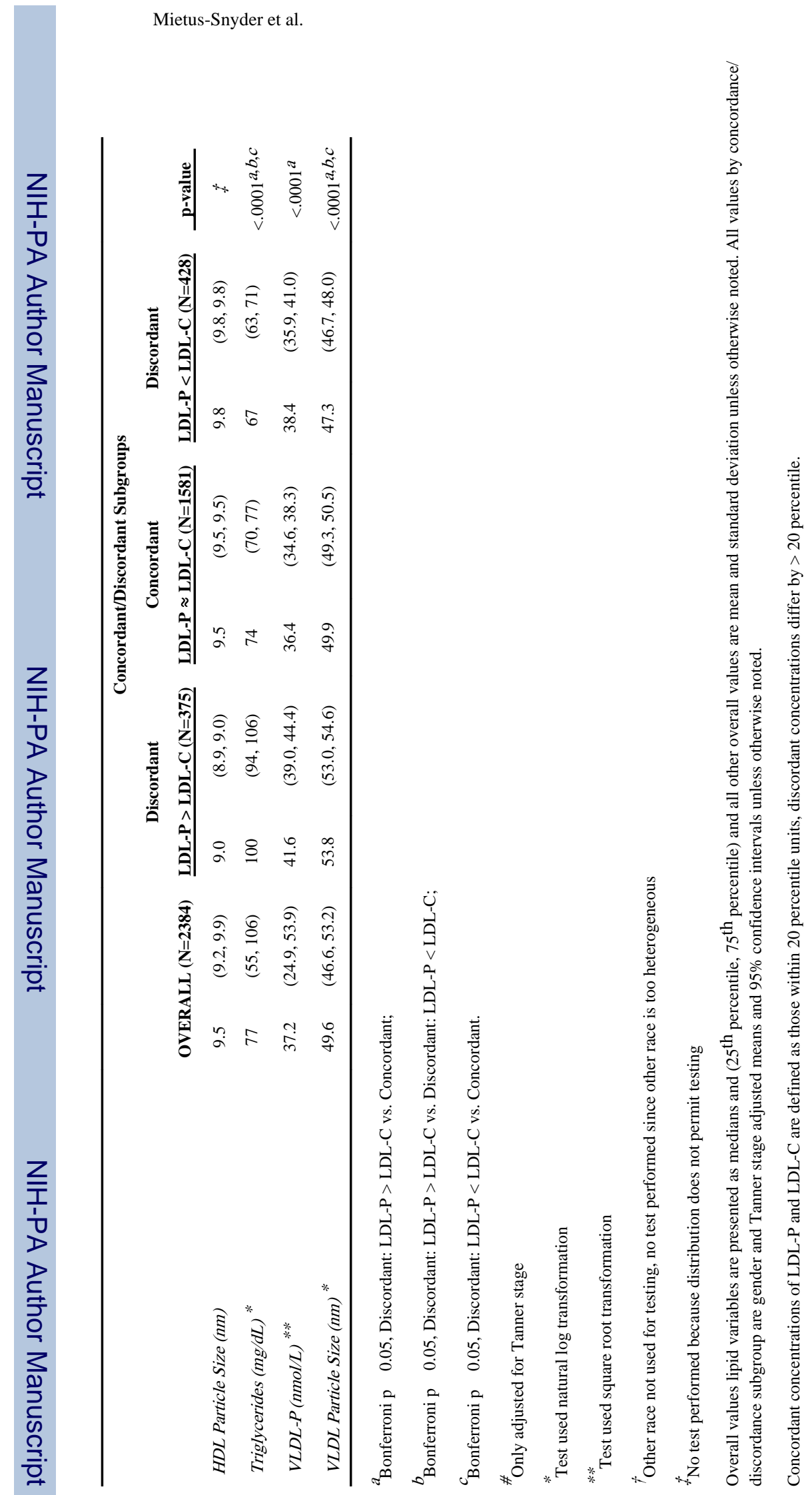

J Pediatr. Author manuscript; available in PMC 2014 August 01. 


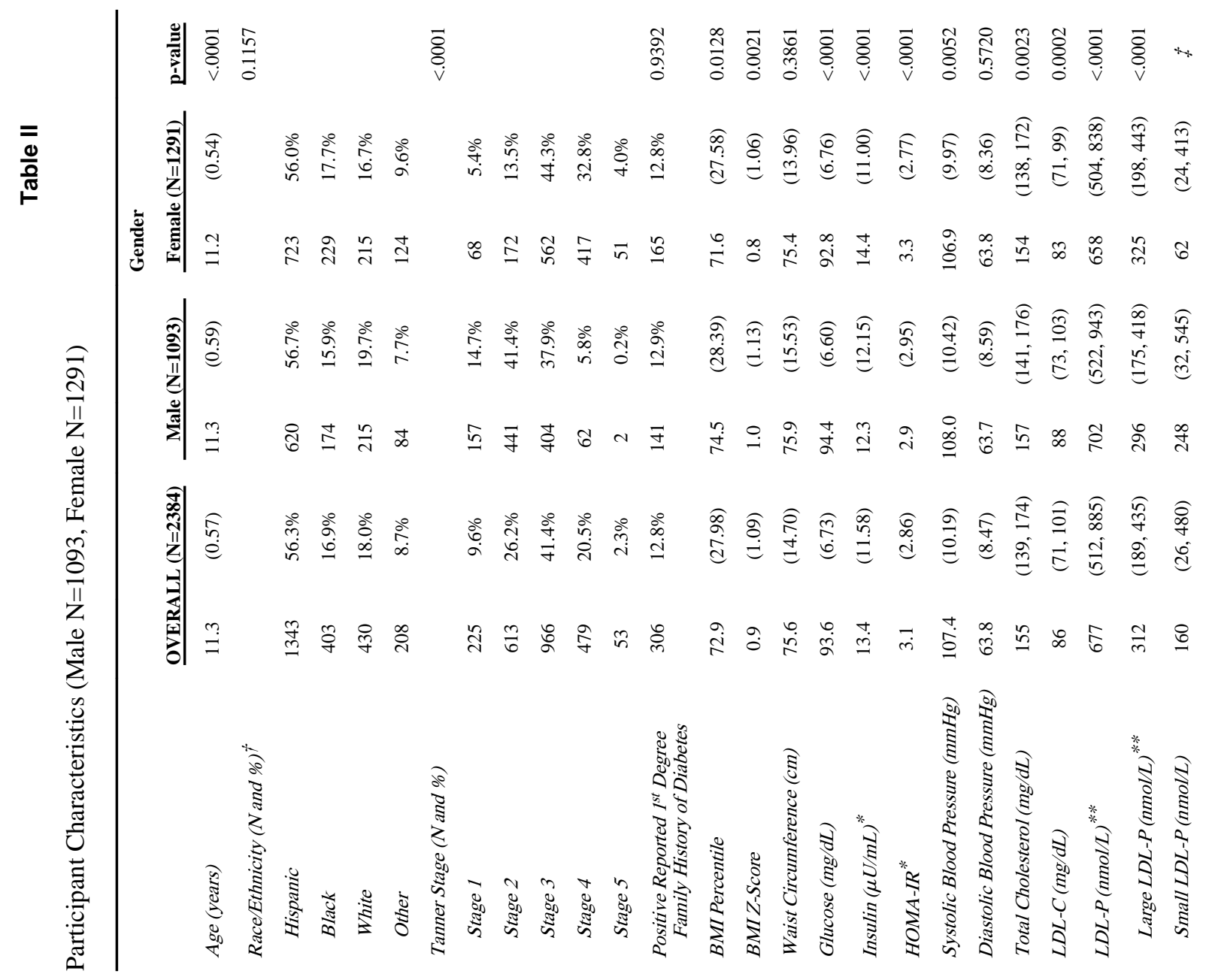




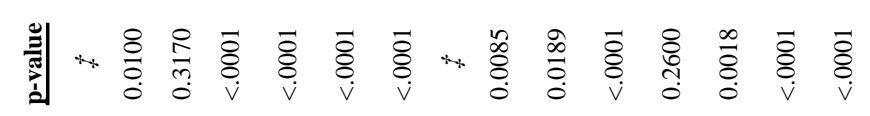

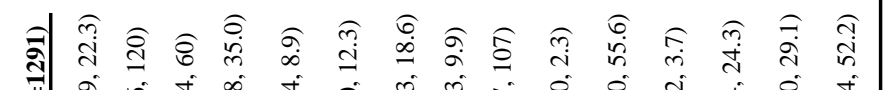

光

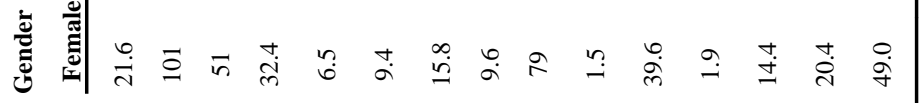

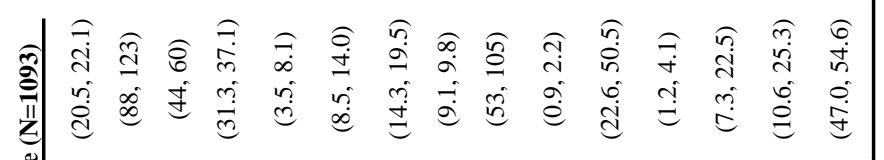

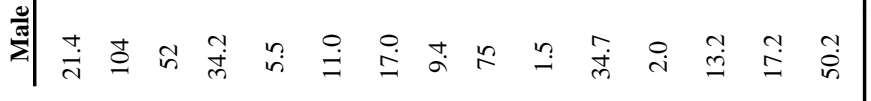

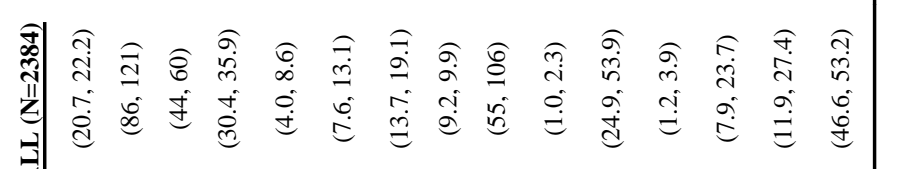

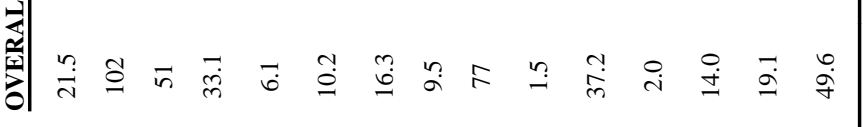




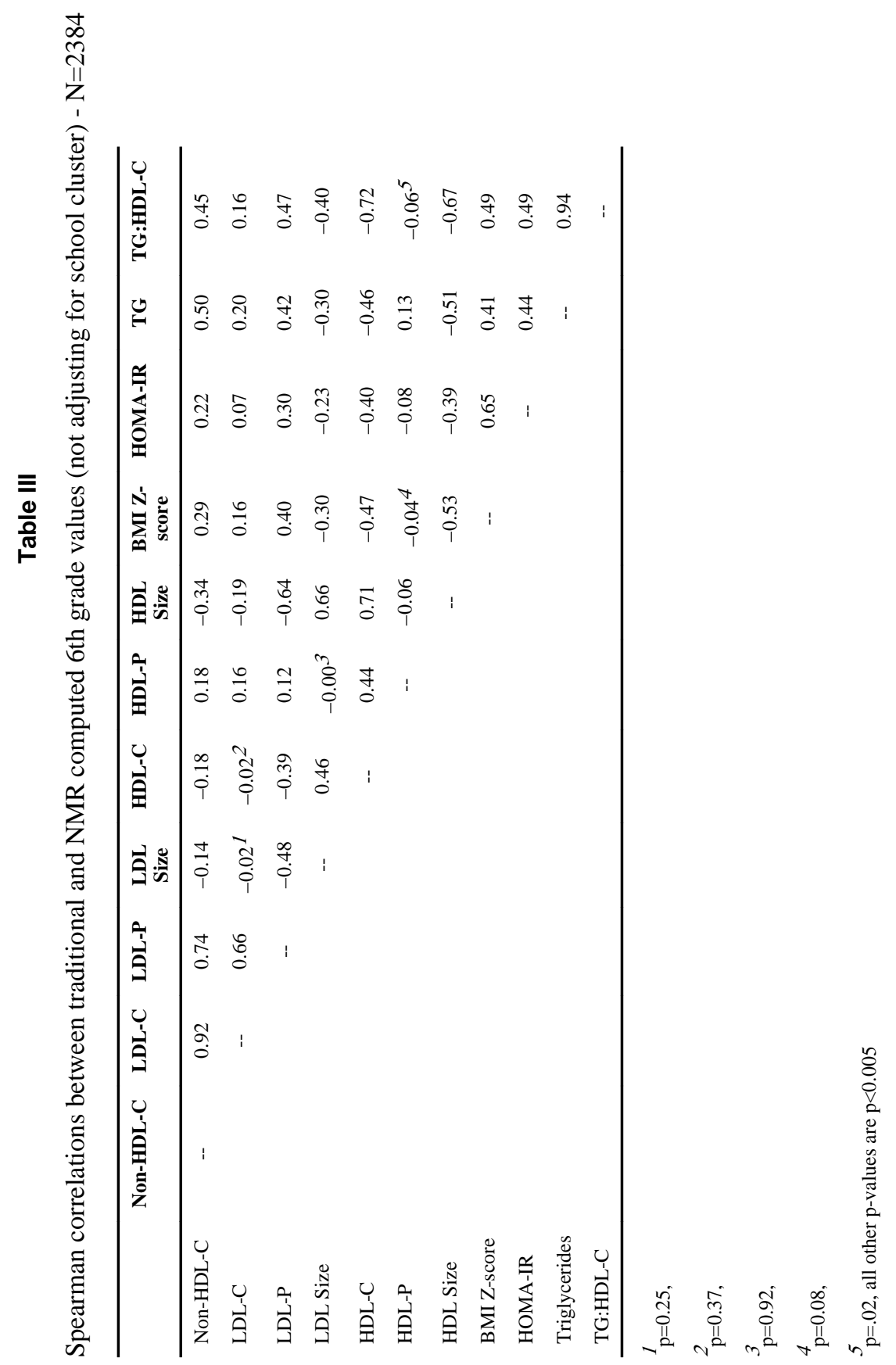




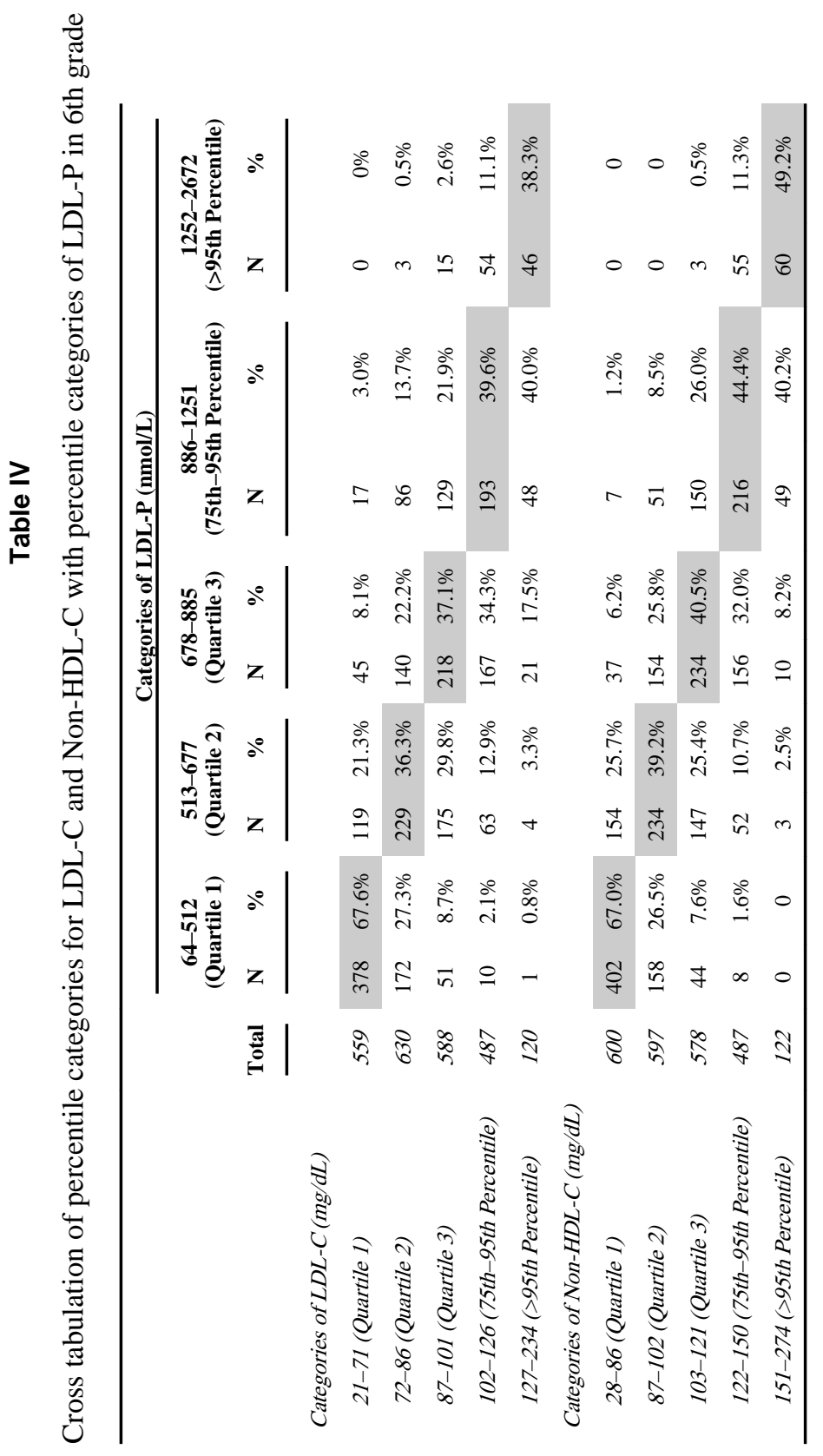

